\title{
ANALOG-DIGITAL SIMULATION OF PULSE COLUMN CONTROL CHARACTERISTICS
}

\author{
M.S. Thesis Submitted to lowa State University, \\ May 1973
}

A. M. Kelly

Ames Laboratory, USAEC

lowa State University

Ames, lowa 50010

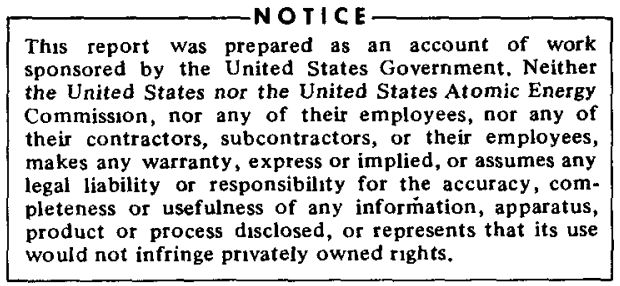

Date of Manuscript: May 1973

PREPARED FOR THE U. S. ATOMIC ENERGY COMMISSION DIVISION OF RESEARCH UNDER CONTRACT NO. W-7405-eng-82. 


\section{DISCLAIMER}

Portions of this document may be illegible in electronic image products. Images are produced from the best available original document. 
This report was prepared as an account of work sponsored by the United States Government. Neither the United States nor the United States Atomic Energy Commission, nor any of their employees, nor any of their contractors, subcontractors, or their employees, makes any warranty, express or implied, or assumes any legal liability or responsibility for the accuracy, completeness or usefulness of any information, apparatus, product or process disclosed, or represents that its use would not infringe privately owned rights.

Available from: National Technical Information Service Department $A$

Springfield, VA 22151

Price: Microfiche $\$ 0.95$ 


\begin{abstract}
Analog-digital simulation of pulse column control characteristics

by

Anthony Michael Kelly

A Thesis Submitted to the

Graduate Faculty in Partial Fulfillment of

The Requirements for the Degree of

MASTER OF SCIENCE
\end{abstract}

Major: Chemical Engineering

Approved:
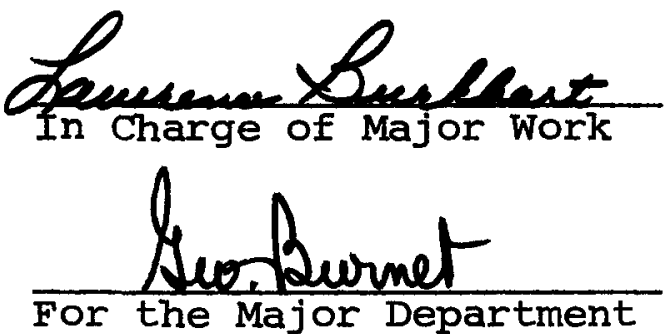

$\frac{c_{3} \text { tranes }}{\text { For the Graduate college }}$

Iowa State University

Ames, Iowa

1973 
TABLE OF CONTENTS

\begin{tabular}{|c|c|}
\hline & Page \\
\hline ABSTRACT & $\mathrm{v}$ \\
\hline NOMENCLATURE & vi \\
\hline INTRODUCTION & 1 \\
\hline LITERATURE REVIEW & 4 \\
\hline Pulse Column Simulation and Control & 4 \\
\hline Control scheme & 7 \\
\hline DEVELOPMENT OF PULSE COLUMN SIMULATION & 9 \\
\hline Theory & 9 \\
\hline Analog Model & 15 \\
\hline DEVELOPMENT OF CONTROL STRATEGY & 19 \\
\hline Predictive Control & 19 \\
\hline $\begin{array}{l}\text { Steady state gain } \\
\text { Dynamic compensation }\end{array}$ & $\begin{array}{l}21 \\
21\end{array}$ \\
\hline Computer Control & 27 \\
\hline RESULTS AND DISCUSSION & 34 \\
\hline Pulse Column Simulation & 34 \\
\hline Control system & 37 \\
\hline CONCLUSIONS & 49 \\
\hline IITERATURE CITED & 50 \\
\hline ACKNOWLEDGMENTS & 52 \\
\hline
\end{tabular}


ABSTRACT

This study was concerned with the development of a predictive control scheme for the pulse column. An analog simulation, developed from laboratory pulse column data, was used to study the control characteristics of the column. A predictive control scheme consisting of a steady state gain term, and a dynamic compensation term, was used. A feedback trimmer was added to compensate for offset and for random input disturbances not detected by the monitor on the input stream.

A small digital computer was used to implement the control algorithm. Direct digital feedback control gave results similar to those obtainable by continuous control. Direct digital predictive control gave much better control than feedback control alone. The direct digital predictive control scheme was able to control multiple and ramp upsets of the pulse column. 


\section{NOMENCLATURE}

A

E

F

H

h

K

k

$\mathrm{K}_{\mathbf{I}}$

$\mathrm{K}_{\mathrm{P}}$

$\mathbf{R}$

S

$S(\Delta t)$

$S_{B}$

1b. Mour

Steady state gain term of predictive control, Equation 7, 1b./hour

$S_{B}\left(S_{I}, \Delta t\right)$ Predicted value of solvent flow rate, Equation 8 , 1b. Mour

$S_{D}(\Delta t) \quad$ Dynamic compensation term of predictive control model, Equation 8, 1b./hour

SI Solvent flow rate into pulse column, Equation 8, 1b. hour

t Time, hour 
$\mathrm{X}$

$\mathbf{Y}$

lb. $\mathrm{HNO}_{3} / \mathrm{lb}$. Solvent

\section{Greek}

$\Delta t \quad$ DDC time element

Subscripts and superscripts 1b. $\mathrm{HNO}_{3} / 1 \mathrm{~b} \cdot \mathrm{H}_{2} \mathrm{O}$

queous phase nitric acid concentration,

Organic phase nitric acid concentration, stage number 


\section{INTRODUCTION}

The pulse column is a hydraulically-pulsed, sieve-plate liquid-liquid extractor. Pulsing the two liquids provides better mixing and increases the extraction efficiency of the column. This results in greater separation per unit of column height. At the same time, the external agitation supplied by the pulse generation does not seriously reduce the throughput capacity.

Pulse columns are widely used in the nuclear industry for rare-earth separations and for nuclear fuel recovery operations. They provide high efficiencies, high throughput rates and stable long term operation--all necessary where one encounters small separation factors requiring a large number of stages, radioactive materials in remote locations where high reliability is desirable, and nuclear criticality restrictions requiring small equipment in order to achieve low process inventories.

In spite of its smaller size the pulse column still shares, with most countercurrent, multistage equipment, a slow rate of approach to steady state. This is caused by the large relative capacitance of the system as compared with its inlet flow rates and often creates control problems because of the time lags involved.

In this work an analog computer was used to simulate a pulse column and the simulation used to study control 
strategies. A small digital computer interfaced to the analog machine was used to develop the control system for the column.

Feedback control is the basic control scheme used to regulate chemical processes. Its purpose is to keep the system output at a predetermined value called the set point. This is done by comparing the output with the set point. The error signal, which is the difference between these two values, is then sent to the final control element in such a way as to return the system output to its original value. An error in the controlled variable must have actually occurred before any control action can take place. Because the pulse column may have large time lags, feedback control does not always give good regulation.

Predictive control is often better able to control processes with large time lags. In a predictive control system, inputs rather than the outputs, are monitored. Any disturbance in the measured input is then used to predict what the final control element should be if the output is to remain at a given set point. By monitoring the input rather than the output, corrective action can be taken as soon as the upset has occurred. In feedback control, the upset must propagate through the system and produce a change in the output before any corrective action can be initiated. In this way a predictive control strategy can be used to 
avoid having to cope with the large time lag between input and output of the process. Because there is no connection between the predictive control loop and the controlled variable, a feedback trimmer is usually added to take care of inaccuracies in the predictive control model and to handle unmonitored upsets in the system.

A small digital computer can be used to implement the control algorithm. Such machines are usually necessary because the predictive portion of the control algorithm requires the use of a computational model of the process in order to predict the new values of the control variable which are fed forward following the detection of an input disturbance. Because they are discrete machines, the digital computers so used employ a technique called direct digital control (DDC). This differs from a continuous controller in that the inputs and outputs are sampled only at discrete intervals and the control signal is sent directly from the computer to the final control element. 


\section{LITERATURE REVIEW}

Pulse Column Simulation and Control

Although the pulse column was first developed in 1935 by Van Dijck (16), the first mathematical model did not appear until the 1950's. In 1958, Troutman and Consiglio (15) made the first attempt at developing a steady state simulation of the pulse column. Their objective was to calculate the percentage loss of uranium in the aqueous stream as a function of the operating variables and the design variables of the column--variables such as column diameter, pulse amplitude, pulse frequency, and flow rates. They developed both analog and digital models based upon those existing correlations which could be found, but because the correlations themselves were found to be good to only \pm 20 percent no tests of the results of the models developed were ever made against actual columns.

Smoot and Babb (14) later developed a digital model which treated the pulse column as a steady state differential contactor. Their model was used to calculate longitudinal concentration profiles for both phases, and to predict the exit concentration of the organic phase. Comparison of the calculations with experimental data gave good results.

Watjen and Hubbard (17) attempted to develop a dynamic model of the pulse column based upon data obtained from 
pulse testing an actual column. Confirmation of the model was tried by comparing frequency response data of the model to data obtained by pulse testing the actual column. However, only qualitative agreement was obtained, probably because of the lack of sophistication in the model and in the method of pulse testing employed.

Biery and Boylan (1) investigated the transient startup behavior of a pulse column and from this information they developed nine possible models for describing the behavior of the column. Although they were of varying degrees of complexity, all of the models had the following features in common.

1. No longitudinal mass diffusion was assumed to take place.

2. Actual stagewise pulsing behavior of the column was ignored, and the column was considered as a continuous countercurrent packed column extractor.

3. Plug flow of the solute in the aqueous phase was assumed.

4. The column was divided into discrete stages.

Model I, which was the simplest model, assumed perfectly mixed equilibrium stages. Model II was similar except that equilibrium contact was not assumed. In Models III, IV, and $V$ neither perfect mixing nor equilibrium contact was assumed. In Models III, IV, and $\mathrm{V}$ the concentrations of each phase 
were taken as the average of the top and the bottom, the bottom, and the top of each stage, respectively. Model VI was a combination of the good points of IV and V. Models VII, VIII, and IX involved the use of a finite difference representation of the differential equations.

Models IV and V gave the best results and Model III the worst results. However, most of the models including Model I, which was the simplest, gave good results if the number of stages employed was large enough.

All of the models were simulated on a digital computer with a varying number of stages. An analog computer was also used, but the size of the available analog equipment limited the number of stages that could be tried for each model to four, except for Model I where fifteen stages could be simulated.

Di Liddo and Walsh (3) developed a dynamic simulation of the pulse column based upon the stagewise pulsation of the fluids. They then used this digital model to study the effects of column operating variables on the dynamics and controllability of the column. Their startup studies gave results similar to those of Biery and Boylan (1). Proportional-integral control was found to be satisfactory for controlling changes as great as 10 percent, but a tendency to flooding was found when an attempt was made to compensate for a 25 percent change in one of the inputs. 
Evans (4) developed a number of second order dynamic models of the pulse column by means of pulse testing. These models were then used in an analog computer simulation of control of the pulse column. Proportional-integral feedback control gave results similar to $\mathrm{Di}$ Liddo and Walsh (3). simple steady state predictive control with a feedback trimmer was used and found to give better control than that obtained with feedback control only.

\section{Control Scheme}

The use of small digital computers for process control is growing rapidly. One reason for this is the computer's ability to implement advanced forms of control such as predictive control. Another is the rapidly falling cost and improved availability of reliable small computers (minicomputers).

Predictive or feedforward control has been shown to give significantly better results compared to feedback control in certain processes. Harris and schechter (5), in a simulation study, showed that predictive control of a chemical reactor gave significant improvement compared to feedback control. Luyben and Gerster (8) in a similar study showed this to be true also for distillation columns. Evans (4) in his simulation of pulse column control demonstrated that predictive control could give better results than 
feedback control alone.

Much has been written $(7,11,13)$ to show how predictive control can be applied to various chemical processes and almost any of the sources indicated can be used to obtain an initial understanding of the subject.

The use of a digital computer for process control is called direct digital control (DDC). DDC means that the output error and the manipulated variable are being sampled discretely rather than continuously and that the computer is sending control signals directly to the final control element. Mosler, Koppe1, and Coughanowr (9, 10), extended the digital compensation theory to include process load changes rather than changes in the set point. They showed that DDC gave results that compared favorably with those obtained from optimally tuned conventional controllers. Cadzow and Martens (2) give a good mathematical analysis of DDC and computer control systems.

There is little mention in the literature of actual computer control of an industrial process $(6,12)$. Although such operations are becoming more widespread, much of the work is still proprietary. 
DEVELOPMENT OF PULSE COLUMN SIMULATION

Theory

The pulse column first came into common use as an extractor in the reprocessing of irradiated fuels from nuclear reactors. Because the recovery of unused fuel material is so important, very little of it is allowed to leave with the waste products from the reprocessing plant. This means that the control scheme of such a pulse column must be very precise and that the uranium content of the raffinate or waste stream is frequently the controlled variable.

In many nuclear fuel recovery processes dissolved fuel is present as nitrates in a nitric acid solution and the acid concentration is important because it has a significant effect upon the distribution coefficient of the uranium and plutonium. In this particular simulation nitric acid was the component studied. It entered the pulse column in the aqueous feed stream and was stripped from the aqueous phase by an organic phase consisting of tributyl phosphate (TBP) in a hydrocarbon diluent.

The mathematical models of the pulse column developed by Biery and Boylan (1) ranged from simple to quite complex in nature. They found that if the simulation were made up of a small number of stages neither type gave a good simulation of the experimental data although the more detailed models were better than the simple ones. However, as the 
number of stages in the simulation increased both types began to give excellent simulation of the experimental data. The simulation used in the present work was carried out on an analog computer because the analog computer gave a dynamic simulation of the pulse column. The analog facilities available were able to handle a nine stage simple model based upon the equilibrium stage, uniform mixing model of Biery and Boylan, but were only able to handle four stages of a complex model. It was felt that a nine stage simple model would be better than a four stage complicated model in simulating the experimental data, hence the simple model was used.

The nonlinear, time varying differential equations necessary to describe the pulse column were derived by making an unsteady state material balance around a typical stage, $j$, and assuming ideal stages. Other assumptions made in the derivation were that the holdup in each stage was constant, that the holdup was a function of column height, that the steady state flow rates did not vary from stage to stage, and that the aqueous flow rate was constant.

The unsteady state material balance for $\mathrm{HNO}_{3}$ in stage $j$, shown in Figure 1 , can be written as,

$$
{ }_{j} \frac{d}{j d t} X_{j}+h \frac{d}{j d t} Y_{j}=A X_{j-1}-A X_{j}+S Y_{j+1}-S Y_{j}
$$

The equilibrium relation is, 


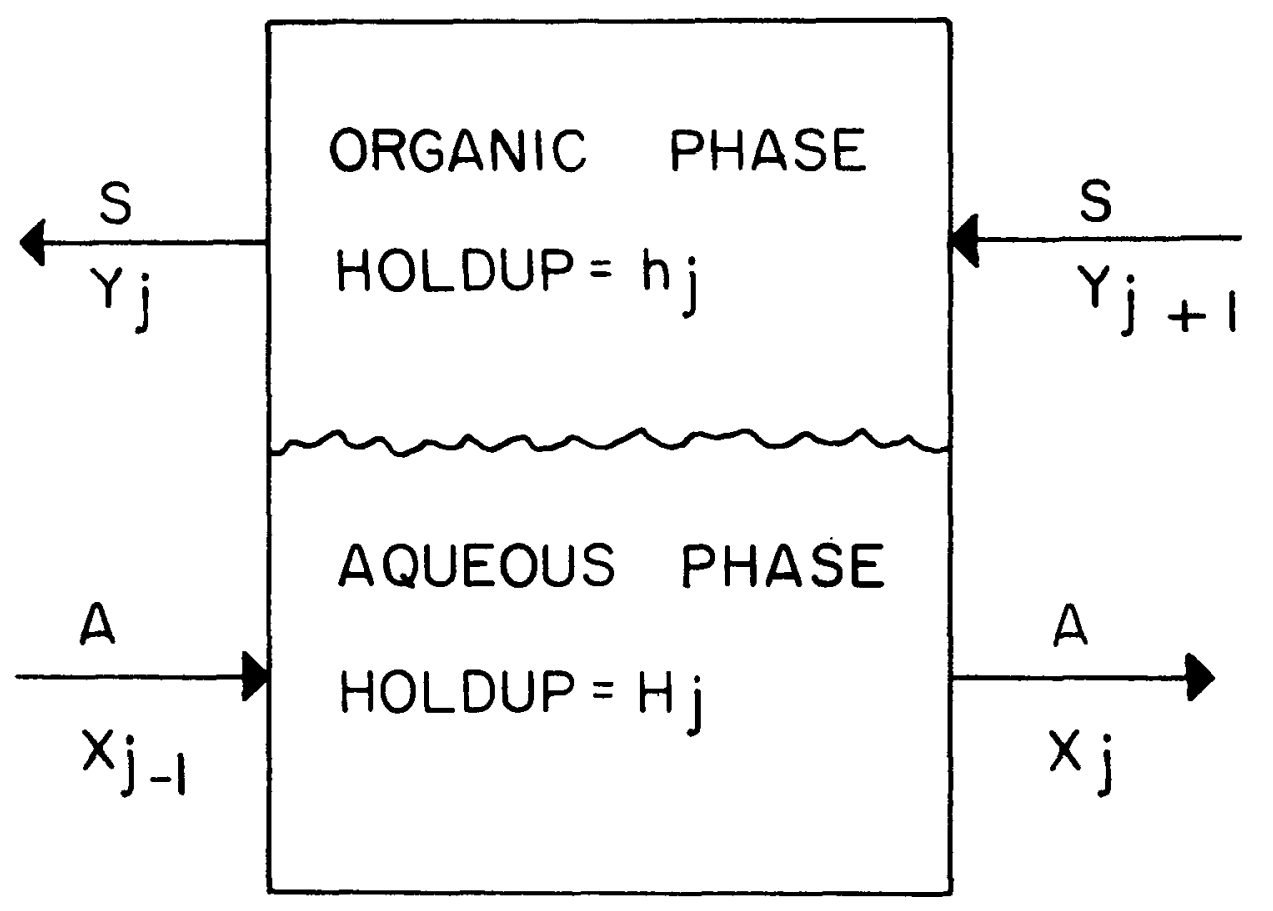

$j^{\text {th }}$ STAGE

Figure 1. General equilibrium stage of the pulse column 


$$
Y_{j}=k_{j} X_{j}
$$

The distribution coefficient is constant for a particular stage, $j$, but varies as a function of stage number. Equation 2 can then be used to eliminate the organic phase concentrations from Equation 1 . Equation 1 then becomes,

$$
H \frac{d}{j d t} x_{j}+h_{j} k \frac{d}{j d t} x_{j}=A x_{j-1}-A x_{j}+S k_{j+1} X_{j+1}-S k_{j} X_{j} .
$$

Solving Equation 3 for the time derivative gives,

$$
\frac{d}{d t} x_{j}=\frac{A\left(x_{j-1}-x_{j}\right)}{H_{j}+h_{j} k_{j}}+\frac{s\left(k_{j+1} x_{j+l}-k_{j} x_{j}\right)}{H_{j}+h_{j} k_{j}} \text {. }
$$

The actual pulse column can be represented by 16 equilibrium stages as shown in Figure 2. However, the analog computer facilities available could handle only nine stages. This meant that a nine stage model had to simulate the operation of a 16 stage pulse column. This was done by developing a pseudo-equilibrium line. By moving the actual equilibrium line further away from the operating line each simulated stage was able to achieve a greater separation so that the nine stage simulation in Figure 3 achieved the same total separation achieved in Figure 2. The particular pseudoequilibrium line shown in Figure 3 gave a simulated response 


\section{3}




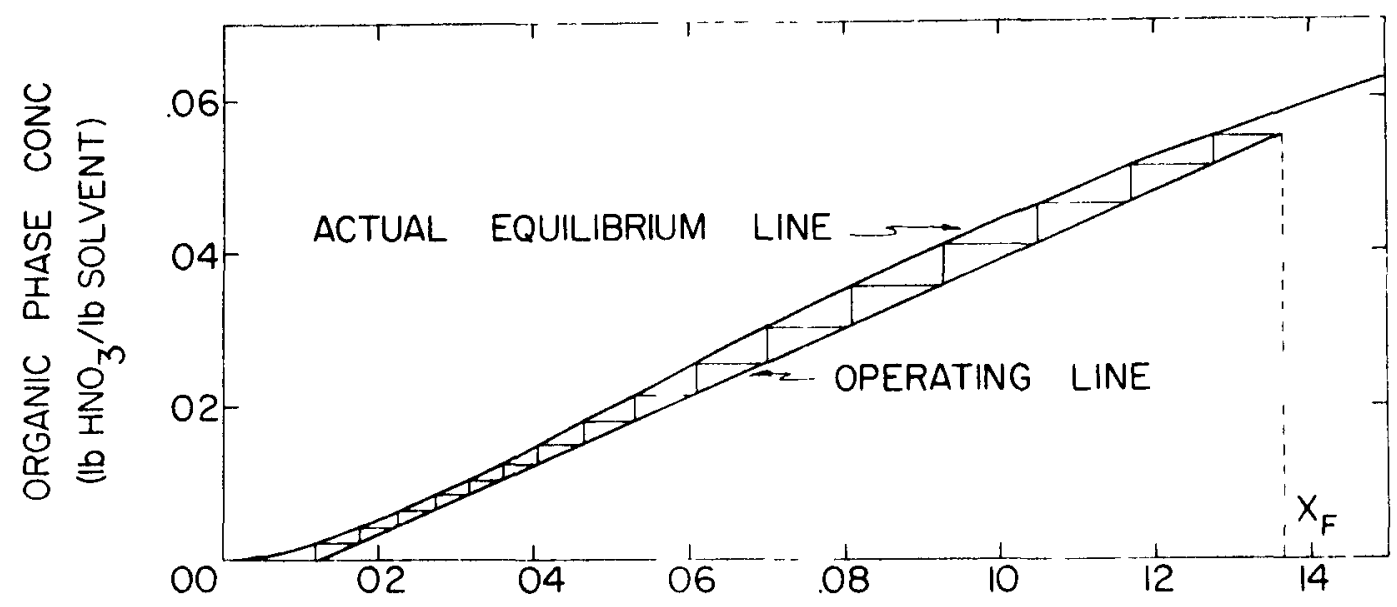

AQUEOUS PHASE CONC. ( $\left.\mathrm{b} \mathrm{HNO}_{3} / \mathrm{lb}_{2} \mathrm{O}\right)$

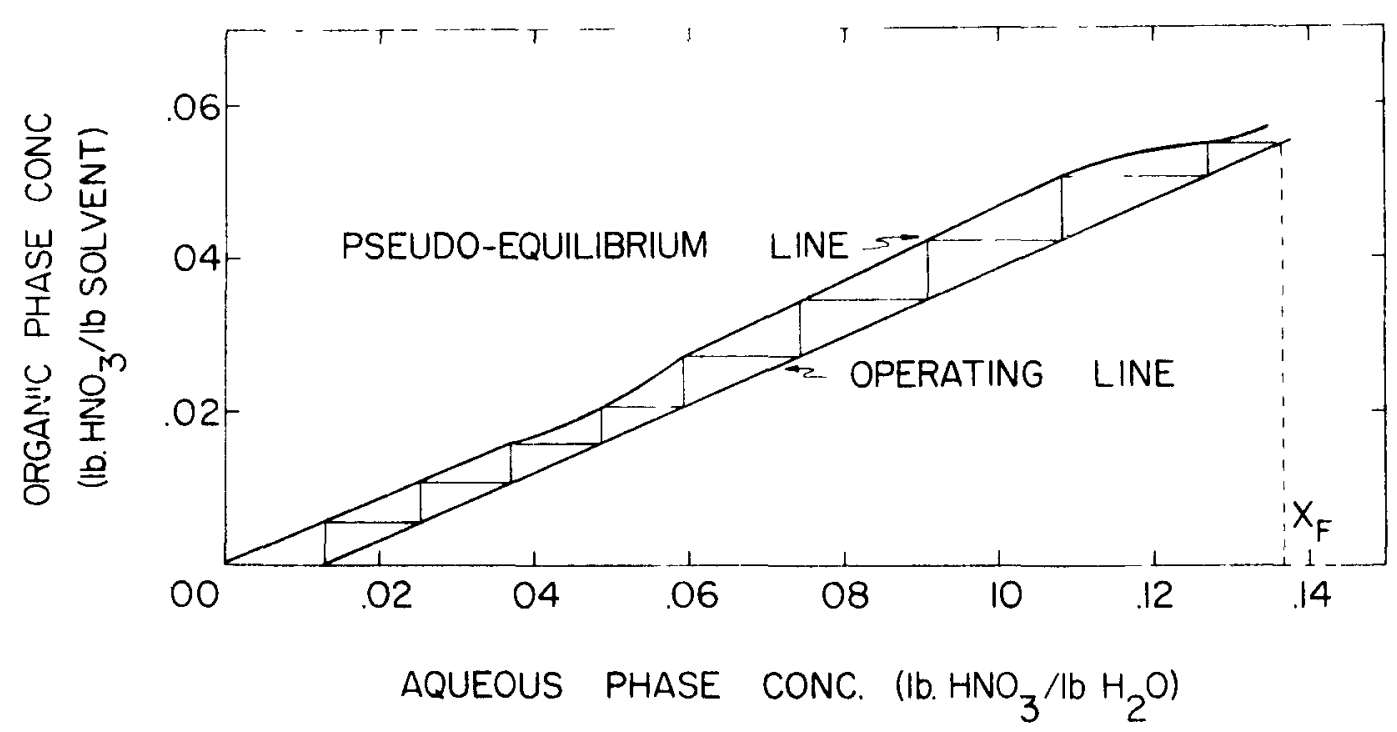


that produced the best fit to experimental data. The pseudoequilibrium line was made by increasing the distribution coefficient in Equation 2. Equation 2 becomes,

$$
\mathrm{Y}_{j}=\mathrm{K}_{\mathrm{j}} \mathrm{x}_{j},
$$

where $k_{j}$ is the new distribution coefficient for each stage. Equation 4 then becomes,

$$
\frac{d}{d t} x_{j}=\frac{A\left(x_{j-1}-x_{j}\right)}{H_{j}+h_{j} K_{j}}+\frac{s\left(K_{j+1} x_{j+1}-K_{j} x_{j}\right)}{H_{j}+h_{j} K_{j}} \text {. }
$$

The feed stage is stage one. This means that $\mathrm{x}_{0}$ is the feed concentration and $x_{1}$ represents the aqueous phase concentration that is in equilibrium with the extract concentration leaving the pulse column. The last stage is the raffinate stage so $x_{9}$ is the raffinate concentration leaving the pulse column. For the last stage $x_{10}$ is zero because there is no $\mathrm{HNO}_{3}$ in the solvent entering the pulse column.

\section{Analog Model}

Two analog computers, an EAI TR-48 and an EAI TR-20, were slaved together to provide the necessary analog computer facilities for simulating the pulse column. Equation 6 was then scaled and used to describe each of the nine stages as shown in the analog computer circuit diagram in Figure 4. The raffinate concentration is the output of 


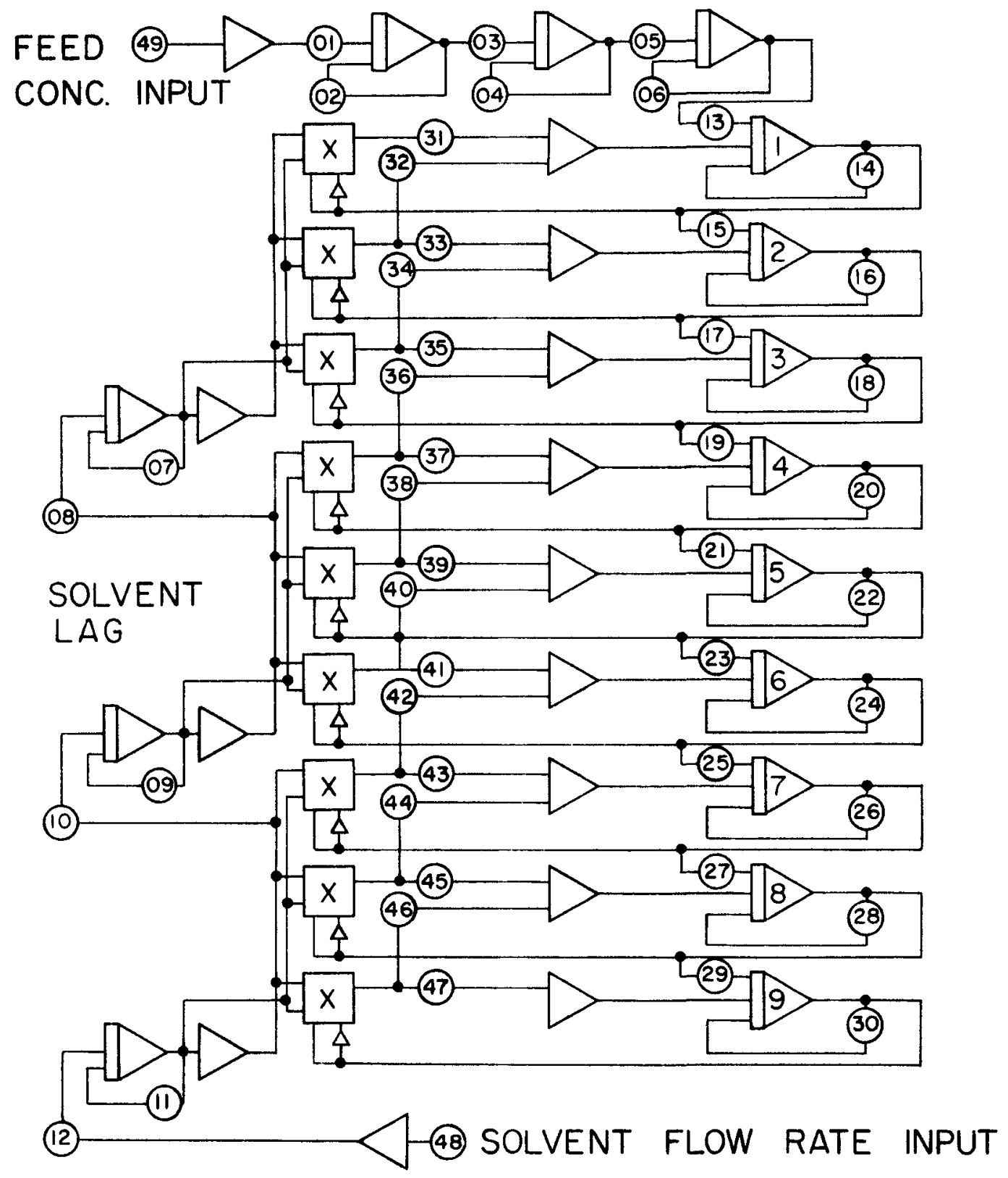

Figure 4. Analog circuit diagram of pulse column simulation 
stage nine. The solvent lag section was made of three first order time lags inserted in the solvent flow stream entering stages 3, 6, and 9. These lags helped provide better dynamic similarity between the nine stage simulation and the experimental data.

The chief fault of the equilibrium stage, uniform mixing model of the pulse column was the lack of an adequate time lag in the raffinate response curve to produce the kind of responses to changes in feed concentration that are observed experimentally. For this reason three first order time lags were also inserted in the feed concentration input section to give a better approximation to the experimental raffinate response curves reported by Biery and Boylan (1).

Table 1 shows the settings for the potentiometers in Figure 4. These numbers represent the scaled coefficients of the $\mathrm{x}$ values in Equation 6 . Values of the aqueous and organic phase holdups and flow rates used in Equation 6 come from experimental data. The distribution coefficient, $\mathrm{K}_{j}$, comes from the pseudo-equilibrium line in Figure 3. These values have been time scaled so that one hour of real time equals 40 seconds of machine time. The values of the $\mathrm{HNO}_{3}$ concentration in each stage have been scaled up in magnitude by a factor of five to reduce machine errors. 
Table 1. Analog potentiometer settings

\begin{tabular}{|c|c|c|c|}
\hline $\begin{array}{l}\text { Pot. } \\
\text { Number }\end{array}$ & Setting & $\begin{array}{l}\text { Pot. } \\
\text { Number }\end{array}$ & setting \\
\hline $\begin{array}{l}01 \\
02 \\
03 \\
04 \\
05\end{array}$ & $\begin{array}{l}0.247 \\
0.247 \\
0.297 \\
0.297 \\
0.299\end{array}$ & $\begin{array}{l}26 \\
27 \\
28 \\
29 \\
30\end{array}$ & $\begin{array}{l}0.362 \\
0.364 \\
0.360 \\
0.360 \\
0.359\end{array}$ \\
\hline $\begin{array}{l}06 \\
07 \\
08 \\
09 \\
10\end{array}$ & $\begin{array}{l}0.299 \\
1.000 \\
1.000 \\
1.000 \\
1.000\end{array}$ & $\begin{array}{l}31 \\
32 \\
33 \\
34 \\
35\end{array}$ & $\begin{array}{l}0.552 \\
0.601 \\
0.561 \\
0.558 \\
0.553\end{array}$ \\
\hline $\begin{array}{l}11 \\
12 \\
13 \\
14 \\
15\end{array}$ & $\begin{array}{l}1.000 \\
1.000 \\
0.365 \\
0.362 \\
0.359\end{array}$ & $\begin{array}{l}36 \\
37 \\
38 \\
39 \\
40\end{array}$ & $\begin{array}{l}0.555 \\
0.560 \\
0.565 \\
0.553 \\
0.544\end{array}$ \\
\hline $\begin{array}{l}16 \\
17 \\
18 \\
19 \\
20\end{array}$ & $\begin{array}{l}0.357 \\
0.359 \\
0.359 \\
0.361 \\
0.361\end{array}$ & $\begin{array}{l}41 \\
42 \\
43 \\
44 \\
45\end{array}$ & $\begin{array}{l}0.507 \\
0.485 \\
0.474 \\
0.477 \\
0.476\end{array}$ \\
\hline $\begin{array}{l}21 \\
22 \\
23 \\
24 \\
25\end{array}$ & $\begin{array}{l}0.364 \\
0.364 \\
0.365 \\
0.368 \\
0.363\end{array}$ & $\begin{array}{l}46 \\
47 \\
48 \\
49\end{array}$ & $\begin{array}{l}0.478 \\
0.476 \\
0.722 \\
0.684\end{array}$ \\
\hline
\end{tabular}


DEVELOPMENT OF CONTROL STRATEGY

\section{Predictive Control}

Predictive or feedforward control is a method of control whereby the output variable is corrected by the control variable to remain at the set point as soon as an input disturbance is detected. Feedback control, on the other hand, cannot be used to correct a disturbance in the system until its effect has propagated through the system and produced a change in the output variable that is being controlled.

For most processes feedback control is usually the simplest and most economical form of control. However, if a system has large time lags, large dead times, or frequent upsets in it then feedback control may give poor regulation or may even be unstable. In predictive control inputs, rather than outputs, of the system are monitored. Since it is usually neither practical nor economical to measure all of the input variables, only those where input disturbances are likely to be found are monitored. When an upset is noticed a new value of the control variable is calculated which will keep the system at the desired set point. This new value for the control variable must be calculated using a mathematical model of the system being controlled. Hence model development is an integral part of designing a predictive or feedforward control algorithm. 
Because predictive control corrects for only measured input disturbances it is blind to disturbances which may arise elsewhere in the system. A feedback trimmer is usually added to correct this fault. It also serves to eliminate any offset caused by the fact that the predictive control model is usually not an exact representation of the system and will thus produce a new value of the control variable which is not entirely accurate.

Predictive control models generally consist of two parts. There is a steady state term and a dynamic compensation term. The steady state term predicts what the control variable will have to be in order to keep the output at the desired set point. If just the steady state output is desired then this gain is sent to the controller. This sudden change in the value of the control variable introduces transients in the output. If these transients produce an unsatisfactory effect upon the output then dynamic compensation may also be added.

In this system the $\mathrm{HNO}_{3}$ concentration in the raffinate stream was the output variable. The input variable was the $\mathrm{HNO}_{3}$ feed concentration, and the control variable was the TBP solvent flow rate. The control criterion was that the output variable, the raffinate concentration of $\mathrm{HNO}_{3}$, be kept at a specific set point. 
Steady state gain

The steady state gain term used for the predictive control model in the system was obtained by fitting a semilogarithmic equation to a map of constant raffinate output contours. These contours were obtained by plotting the raffinate output of the column for various combinations of feed concentration and solvent flow rate as shown in Figure 5. A raffinate concentration of $0.0130 \mathrm{lb} \cdot \mathrm{HNO}_{3} / 1 \mathrm{~b} \cdot \mathrm{H}_{2} \mathrm{O}$ was chosen as the set point for this simulation.

A semi-logarithmic equation of the form,

$$
s_{B}=a_{1} \log (F)+a_{2}
$$

was used to fit the contour curve representing the desired set point. The $a_{i}$ were adjusted to give the best fit. Equation 7 is the steady state predictive control model because it relates the control variable, solvent flow rate, to the input variable, feed concentration. If a feed concentration disturbance occurs the new solvent flow rate predicted by Equation 7 will keep the raffinate concentration at its set point value.

\section{Dynamic compensation}

Dynamic compensation was added to eliminate the transients in the raffinate concentration of the pulse column. This compensation term was developed by finding the dynamic function relating the solvent flow rate to feed concentration 


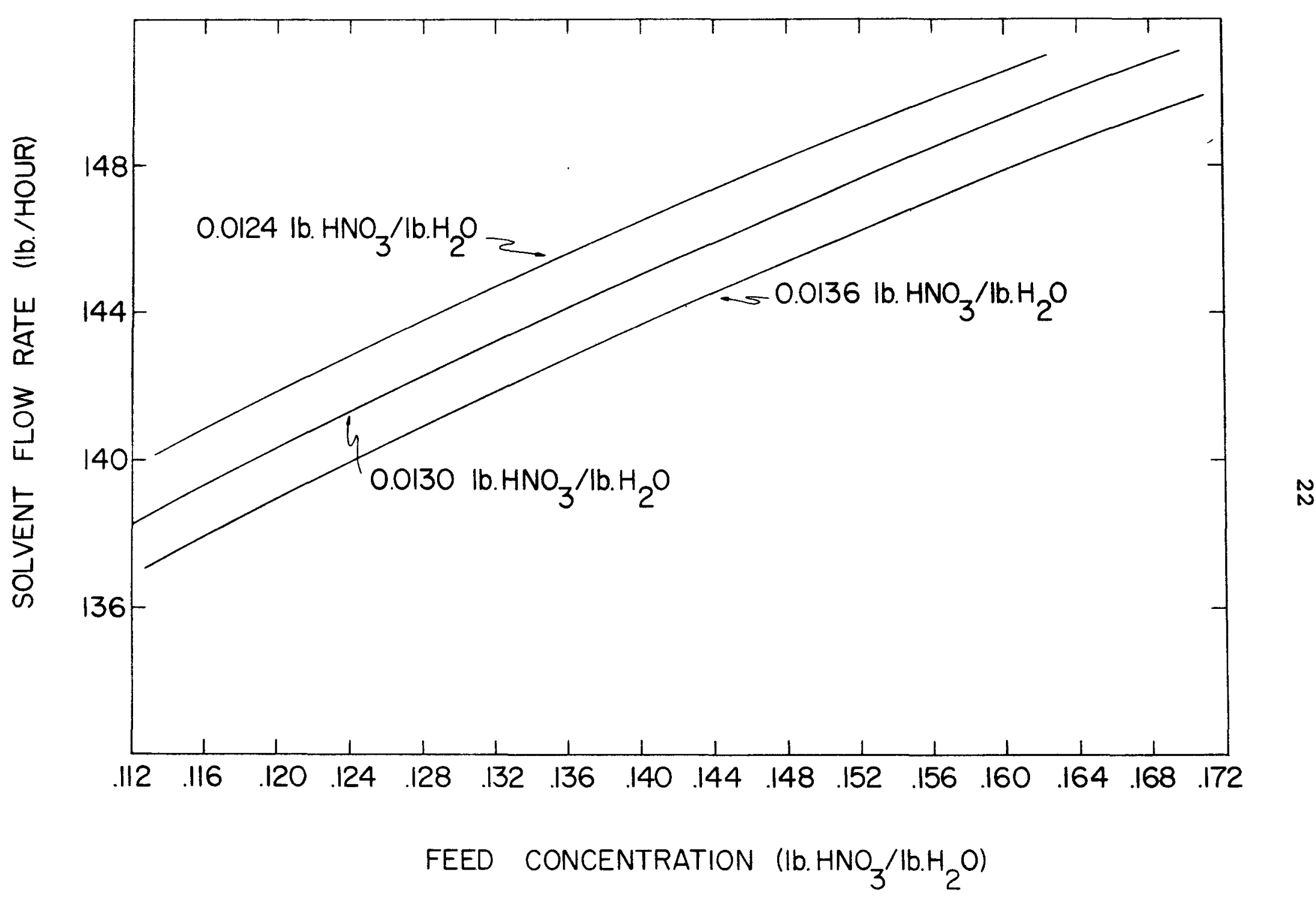

Figure 5. Map of constant raffinate output contours 
changes. First, the open loop responses of the raffinate concentration to changes in feed concentration and solvent flow rate were found. Figure 6 shows these dynamics. These two curves are the dynamic functional representation of how the raffinate concentration responded to changes in feed concentration and solvent flow rate. The curves were normalized so that the steady state gain was unity.

Second, the effect of the raffinate response was eliminated from these two curves because a dynamic compensation term relating solvent flow rate to feed concentration was needed. A point on the dynamic compensation curve in Figure 7 was developed by choosing a particular time in Figure 6 and dividing the percent response of the raffinate to a change in feed concentration at that time by the percent response of the raffinate to a change in solvent flow rate at that time. This was done for a sufficient number of points to obtain the total dynamic compensation curve. Because both individual curves had gains of unity, the dynamic compensation term also had a gain of unity. This method of obtaining the dynamic compensation term has been described in detail by Murrill (11).

The dynamic compensation term was then combined with the steady state gain term to give the solvent flow rate as a function of time,

$$
S_{B}\left(s_{I}, \Delta t\right)=S_{D}(\Delta t)\left(s_{B}-s_{I}\right)+s_{I}
$$




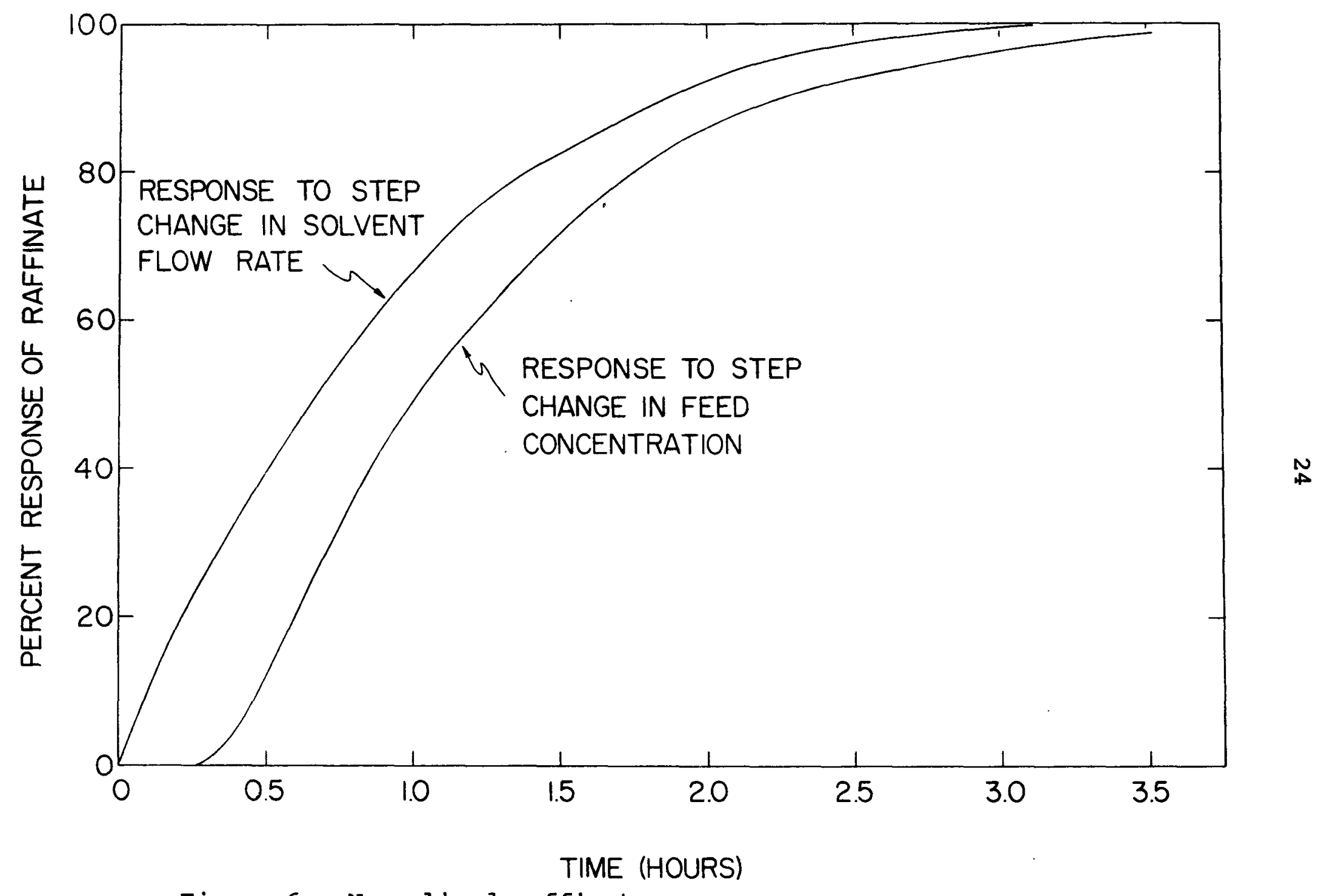

Figure 6. Normalized raffinate response curves 


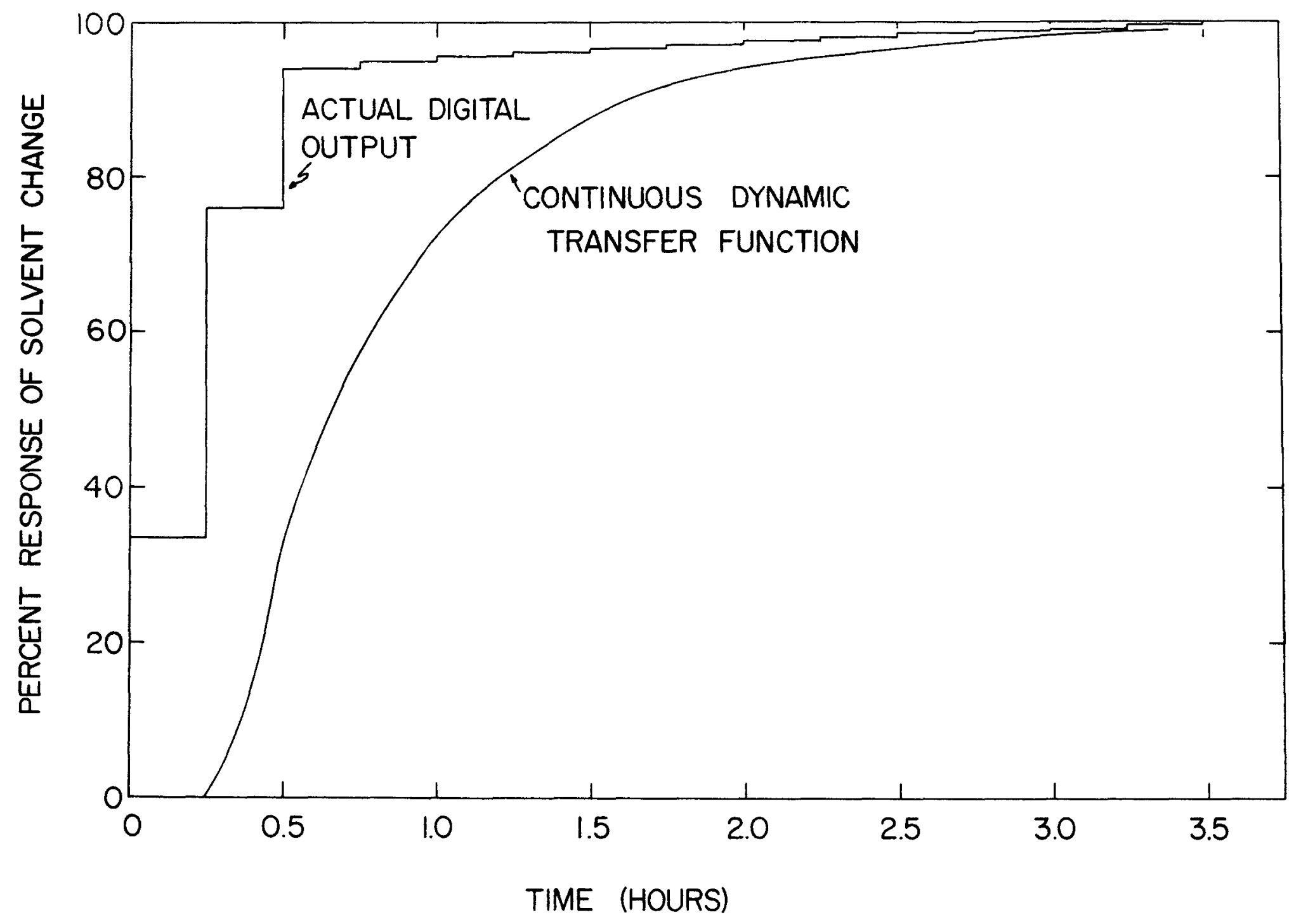

N

Figure 7. Dymamic response of predictive control variable 
$S_{I}$ is the value of the solvent flow rate at the time an upset in the feed concentration is noticed. The dynamic term $S_{D}(\Delta t)$ multiplies the difference between the solvent at the time of the upset and the new predicted value of the solvent flow rate. The difference is used because the solvent flow rate must change from $S_{I}$ to $S_{B}$. The discrete time element, $\Delta t$, is used because the computer applies DDC over discrete time elements.

As mentioned earlier, the steady state gain term is not an exact model of the characteristic set point curves of the analog simulation. For this reason a feedback trimmer was used to correct any offset error. Proportional-integral control was used for the trimmer. The equation for the feedback trimmer is,

$$
S(R)=K_{P} E+\sum K_{I} E \Delta t
$$

This equation is the DDC representation of the traditional equation for proportional-integral control. The complete equation for the control model was then,

$$
S(\Delta t)=S_{B}\left(S_{I} \cdot \Delta t\right)+S(R)
$$

where $s(\Delta t)$ is the new solvent flow rate sent to the pulse column. 


\section{Computer Control}

Figure 8 shows the hardware schematic for the predictive control portion of the pulse column simulation. The total system consists of the analog computer, a small digital computer, a data acquisition system, and a digital-to-analog (D/A) converter.

The pulse column was dynamically simulated on the analog computer. The small digital computer was a Digital Equipment Corporation PDP-8/L minicomputer. It was equipped with a real-time clock so that the computer can effect real-time control. The computer was also equipped with a peripheral expansion system so that it could control external devices. The PDP-8/L uses a software program called FOCAL, a conversational programing language developed by the manufacturer. This was the program language in which the control program was written.

One of the external devices was a Hewlett-Packard data acquisition system. It consists of a 200 position, 3-wire guarded crossbar switch, a scan control unit, and an integrating digital voltmeter. Under program control the scan control selects the proper channel, the crossbar switch then makes the contact with that channel, and the analog signal is sent to the integrating digital voltmeter. The digital voltmeter serves as the analog-to-digital (A/D) converter. The digital signal is then sent to the minicomputer for 


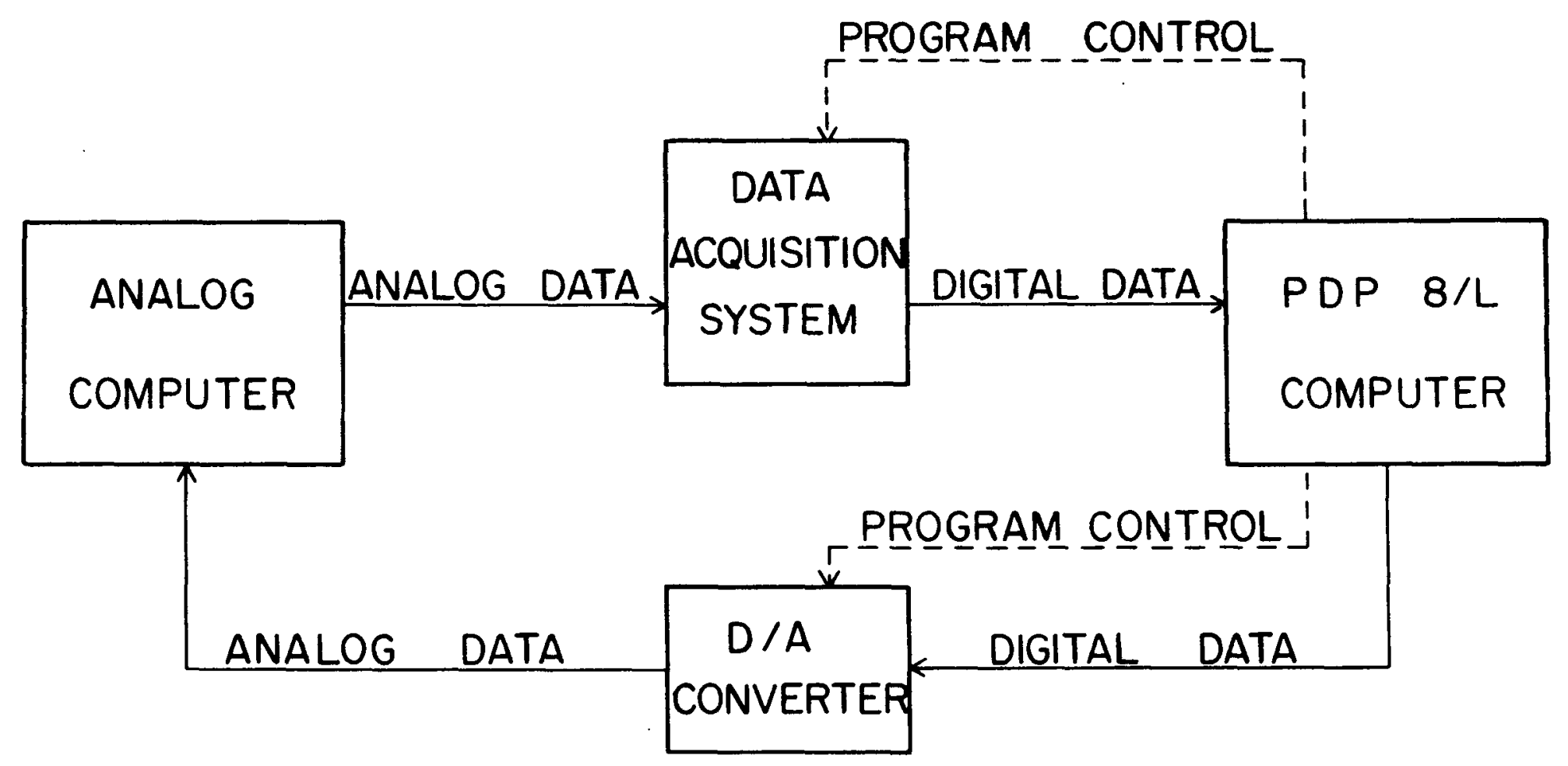

Figure 8. Hardware control diagram with information flow 
further processing.

The other external device was a Heath $D / A$ converter. Because the analog computer can only process analog signals, digital information from the $\mathrm{PDP}-8 / \mathrm{L}$ was sent through the $\mathrm{D} / \mathrm{A}$ converter for conversion to a continuous analog signal.

Two variables were monitored by the predictive control program. The input variable, the feed concentration, was monitored by the predictive section, and the output variable, raffinate concentration, was monitored by the feedback trimmer. The PDP-8/L directed the digital acquisition system to select the proper analog channel needed by the control program. This information was then processed by the control program. If any changes were required in the solvent flow rate the computer directed this information to the $\mathrm{D} / \mathrm{A}$ converter. The $\mathrm{D} / \mathrm{A}$ converter changed the digital representation of the new solvent flow rate to a continuous analog signal, which was then used by the simulation of the pulse column on the analog computer.

Because the PDP- $8 / L$ is a discrete machine it was necessary to employ a form of control called direct digital control (DDC). DDC differs from a continuous controller in that the inputs and outputs are sampled at discrete time intervals. The frequency with which these inputs and outputs are sampled is the variable that characterizes the difference between DDC and a continuous controller. 
Table 2 shows the listing of the computer program used for the control scheme. The first section is the initialization part of the program. The second section shows how the real-time clock monitors the control program. The third section is the predictive control portion of the predictive control program. The fourth section shows the feedback trimmer portion of the predictive control program. The fifth section is the output section for controlling the $D / A$ converter.

The control program follows the procedure given in the flow sheet in Figure 9.

1. Every 10 seconds a new control cycle is initiated.

2. The feed concentration is checked by the predictive control section to see if there has been any changes since the last cycle.

3. If the feed concentration has changed then a new predictive control loop begins. This loop will last 15 control cycles before the dynamic compensation of the predictive control section has reached unity gain. After the first step has been calculated by Equation 8 the raffinate concentration is checked.

4. If there have been no changes in the feed concentration then the program checks to see if it is still in a predictive control loop. If it is, then 
Table 2. Computer listing of control program

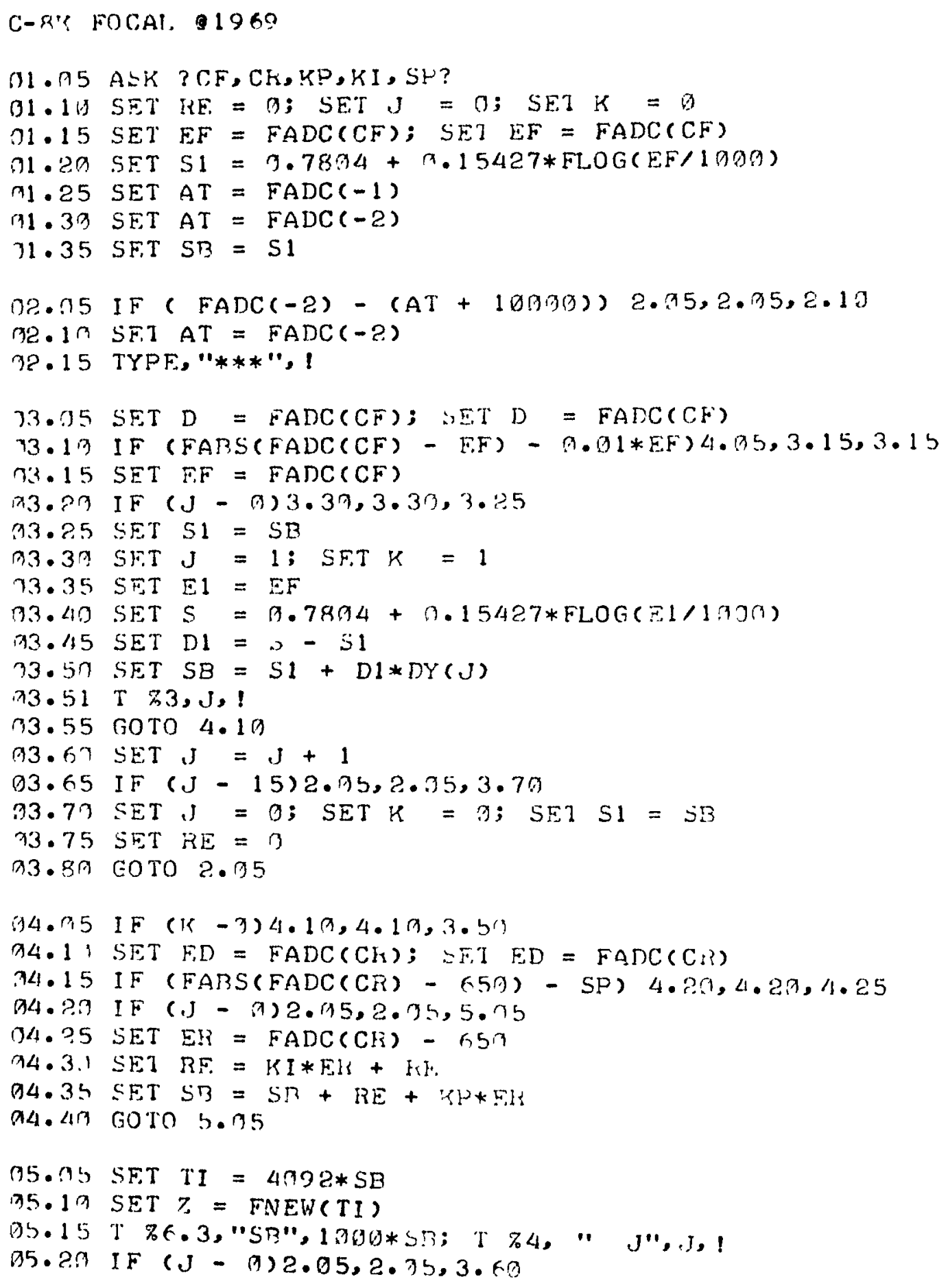




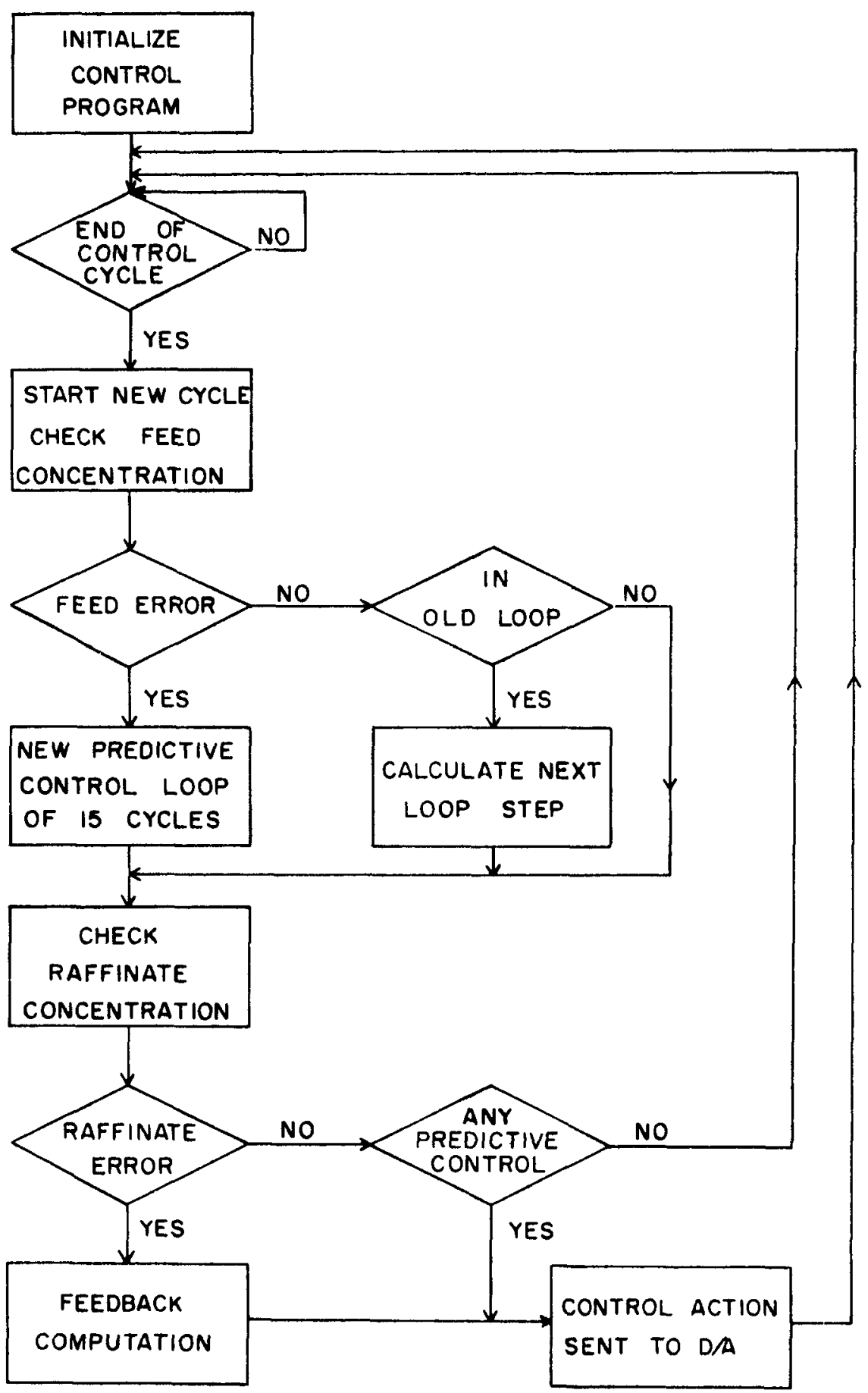

Figure 9. Computer control logic flow sheet 
the next step is calculated by Equation 8 before the raffinate concentration is checked. If the program is not in a control loop then the raffinate concentration is checked directly.

5. If the raffinate concentration has deviated from the set point then the feedback trimmer section takes action by Equation 9. If there was no predictive control or feedback action needed then the control program returns to step one.

6. The predictive and feedback control action are added together as in Equation 10.

7. This control action is then sent to the $D / A$ converter. There is just one output for each control cycle.

8. Control of the program returns to step one until a new control cycle is started and the steps are repeated. 


\section{RESULTS AND DISCUSSION}

\section{Pulse Column Simulation}

In this study the dynamic pulse column simulation was used as a means of determining steady state operating conditions, as a means of obtaining dynamic response characteristics, and as a representation of the pulse column in the control studies.

One dynamic response studied was that of column startup. The column was operated with constant solvent and aqueous flow rates but no acid feed. Then an acid concentration corresponding to that reported by Biery and Boylan (1) was stepped into the column. Figures 10 and 11 show the pulse column simulation of the raffinate and extract startup curves compared to the experimental data. Figure 11 shows the aqueous phase concentration that is in true equilibrium with the extract stream leaving the pulse column. Comparison of the experimental data and the simulation shows that the startup characteristics of the model are indeed quite similar to those of the laboratory extractor for which the model was developed.

Other dynamic responses were obtained for changes in solvent flow rate and feed concentration. These were used in determining the dynamic compensation term, $S_{D}(\Delta t)$, for the predictive control model. It was not possible to compare these simulated responses to experimental data, but the 


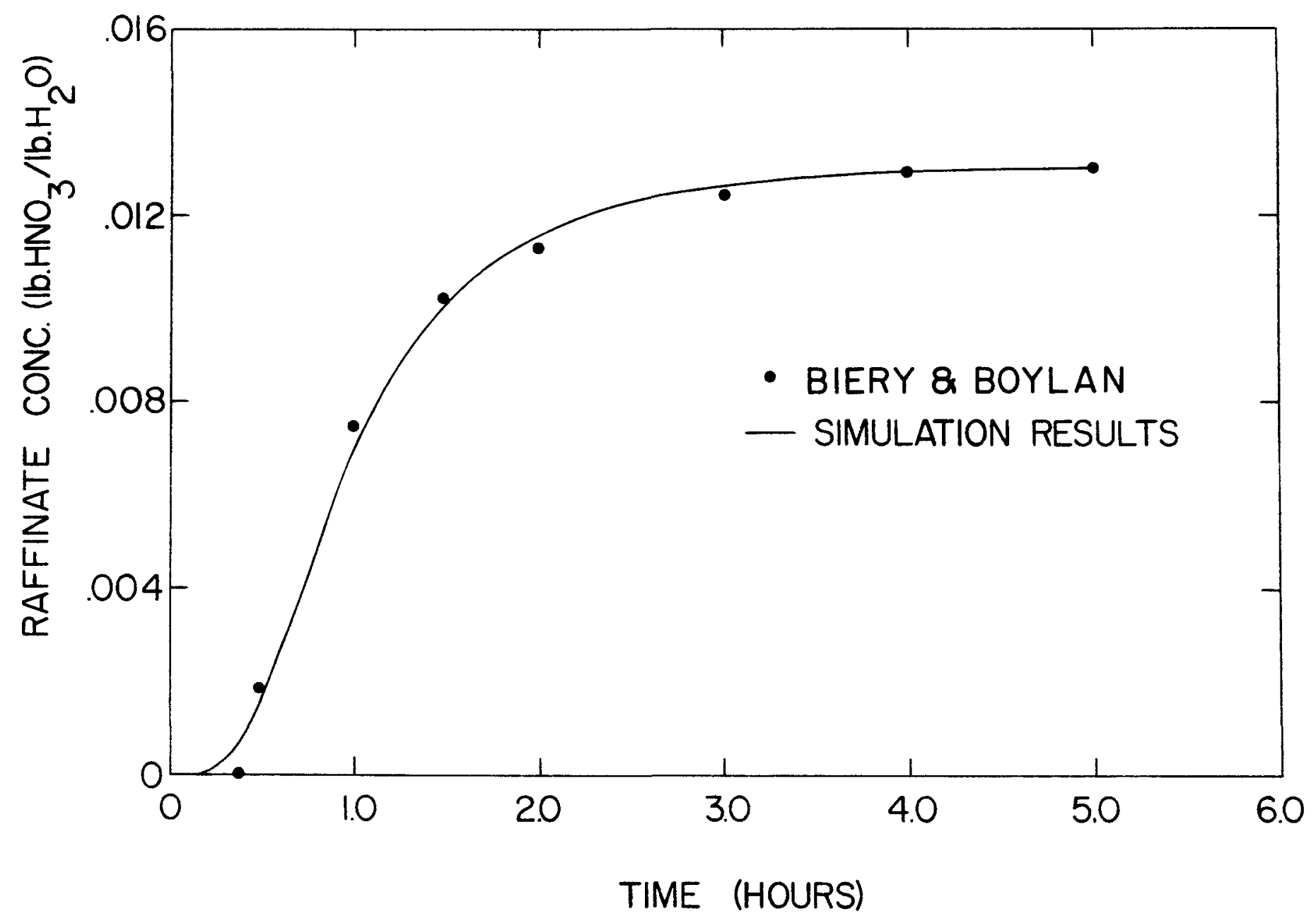

Figure 10. Startup curve of raffinate concentration 


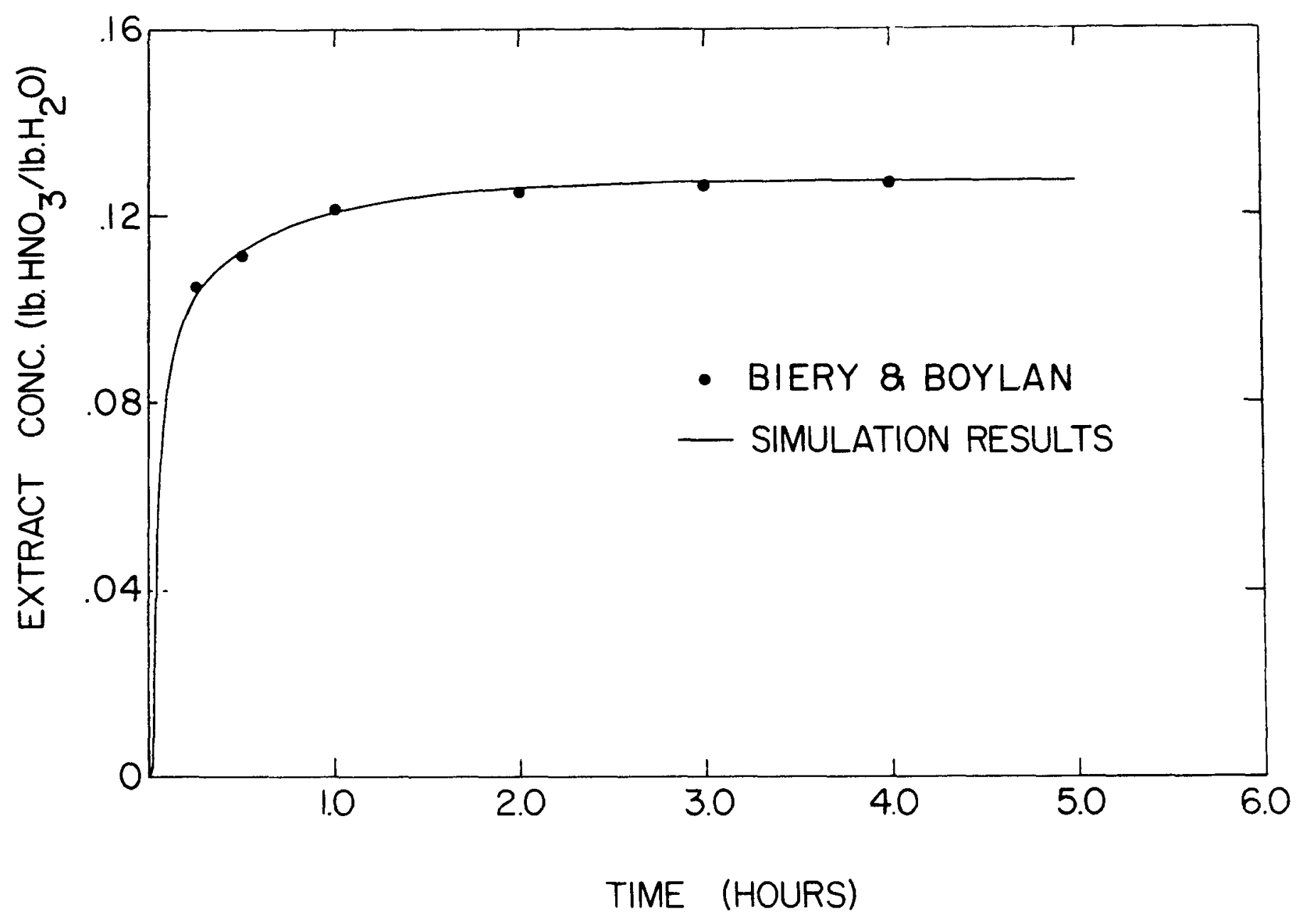

Figure 11. Startup curve of extract concentration 
general form of these simulated responses was similar to those reported by Evans (4).

Control system

The PDP-8/L minicomputer was used to control the analog simulation of the pulse column. The computer implemented a direct digital control (DDC) algorithm by discretely sampling the inputs and outputs. Each control cycle or sample period lasted 10 machine seconds. Since the analog simulation was time scaled so that 40 machine seconds represented 1 real hour, this meant that each control cycle represented 15 minutes of real time.

The first part of the study involved the programming of a conventional feedback control algorithm on the PDP-8/L. One method of tuning the controller to obtain a quarter decay ratio was developed by Ziegler and Nichols and is explained by Murrill (11) and Luyben (7). This method consists of using a proportional feedback control loop and tuning the proportional gain so that for an upset a continuous oscillatory response curve results. The control constants are then derived from the period of oscillation and the proportional gain used.

These derived control settings for proportionalintegral control were then used in the DDC algorithm. Figure 12 shows the comparison of feedback control to an 


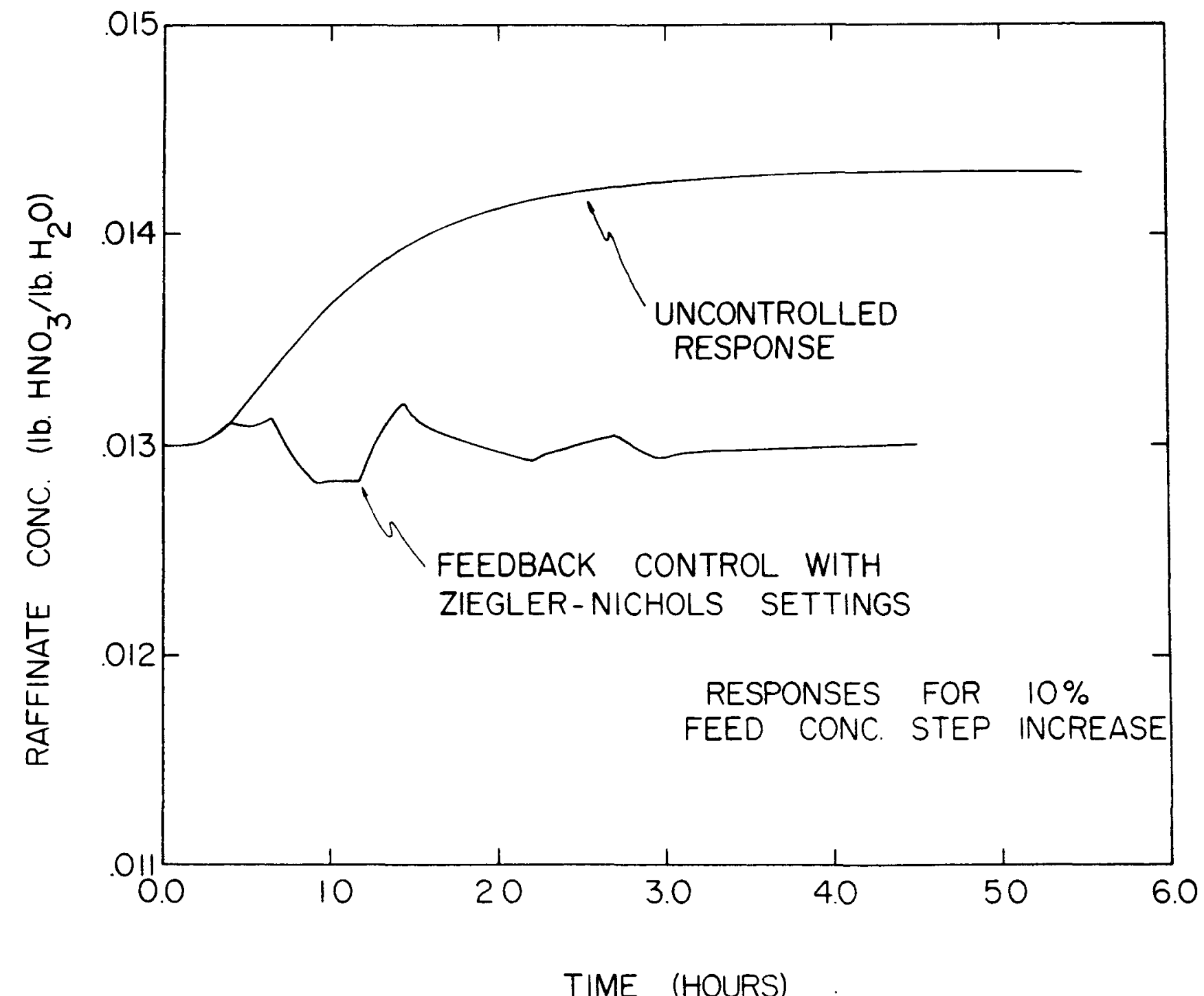

Figure 12. Comparison of feedback control with uncontrolled raffinate response 
uncontrolled raffinate response for a 10 percent step increase in feed concentration. The Ziegler-Nichols method gave results for DDC that compared favorably to control obtainable from a conventional continuous controller. The Ziegler-Nichols settings were for the gains in Equation 9. The real time $\mathrm{K}_{\mathrm{p}}$ value in Equation 9 was $12700 \mathrm{lb}$. solvent per hour $/ \mathrm{lb} \cdot \mathrm{HNO}_{3} / \mathrm{lb} \cdot \mathrm{H}_{2} \mathrm{O}$. The real time $\mathrm{K}_{\mathrm{I}}$ value in Equation 9 was $30400 \mathrm{lb}$. solvent per hour $/ 1 \mathrm{~b} . \mathrm{HNO}_{3} / \mathrm{lb} . \mathrm{H}_{2} \mathrm{O} /$ hour. The real time $\Delta t$ in Equation 9 was 0.25 hours.

DDC is characterized by a certain sampling frequency. This is the frequency at which the inputs and outputs are monitored. The frequency used in this study was 4 samples per hour. This frequency had an effect upon the feedback control responses. Figure 13 compares feedback responses for Ziegler-Nichols settings and softer control settings for very small deviations from the set point. The zieglerNichols settings gave poorer regulation of the raffinate output of the pulse column. This was because the zieglerNichols settings sent a larger control action to the pulse column and overcompensated for the error. This larger control action was fine for large deviations from the set point, as in Figure 12, but for small deviations this overcompensation produced larger errors than the error that was to be eliminated. These larger errors were not noticed 


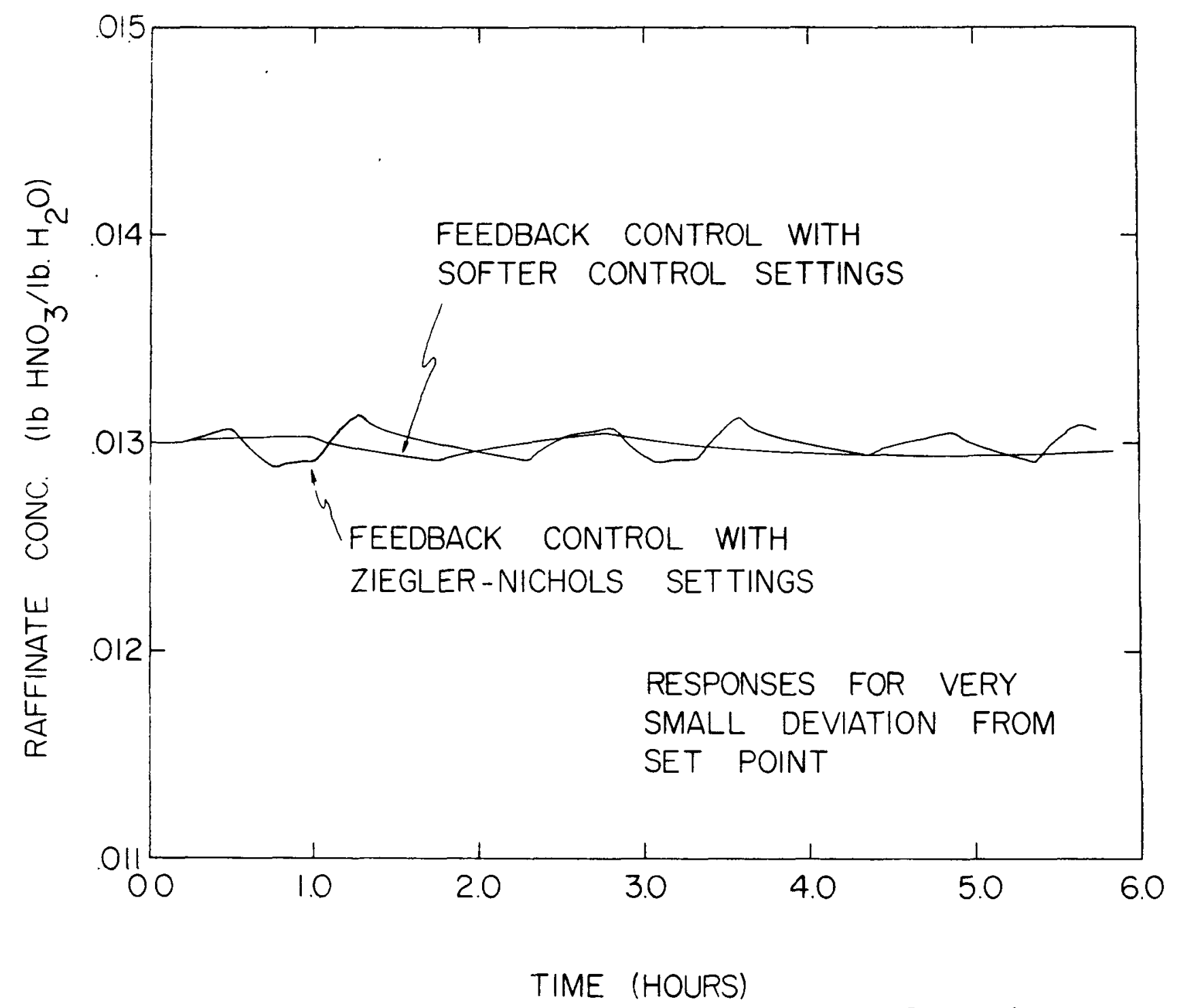

Figure 13. Responses showing the advantage of soft control settings over ZieglerNichols settings for very small deviations from the set point 
until the next control cycle. If the sampling frequency were higher the control program would notice that the raffinate output was returning to the set point and would thus change the control action earlier so overcompensation would not occur. This is because a slower sampling frequency allows a given control action to last longer than a given control action for a fast sampling frequency. This longer acting control action may cause overcompensation as in Figure 13 .

The softer control settings were used in the feedback trimmer for the predictive control scheme. The real time $\mathrm{K}_{\mathrm{P}}$ value used was $5000 \mathrm{lb}$. solvent per hour $/ \mathrm{lb}$. $\mathrm{HNO}_{3} / \mathrm{lb}$. $\mathrm{H}_{2} \mathrm{O}$. The real time $\mathrm{K}_{\mathrm{I}}$ value was $4000 \mathrm{lb}$. solvent per hour $/ 1 \mathrm{~b}$. $\mathrm{HNO}_{3} / \mathrm{lb}$. $\mathrm{H}_{2} \mathrm{O} /$ hour. The real time $\Delta \mathrm{t}$ was 0.25 hours.

The second part of the control study involved the addition of a predictive control algorithm. The predictive control scheme used consisted of a steady state predictive term and a dynamic compensation term. Because DDC was employed the dynamic compensation term was a digital output. The digital compensation output used in the study is shown in Figure 7 along with the continuous compensation curve. The digital compensation output does not precisely represent the continuous output because the digital output compensation rises much faster than the continuous 
compensation curve.

This can be explained by the results of Figure 14 . Figure 14 shows the effect of predictive control compared to an uncontrolled raffinate response for a 10 percent step increase in feed concentration. There are three predictive control curves in Figure 14. If the upset occurred near the beginning of a sample period then the predictive control scheme undercompensated and the output concentration rose slightly before returning to the set point. If the upset occurred near the end of a sample period then the control program noticed it earlier and overcompensated, and thus the output concentration fell slightly before returning to the set point. If the upset occurred in the middle of the sample period then the predictive control scheme produced little deviation from the set point. The particular digital output compensation curve in Figure 7 was used because it made the offset errors equal for upsets occurring at either end of the sample period. If the digital output were closer to the continuous curve in Figure 7 then the offset error for an upset occurring near the beginning of a sample period was larger, but the offset error for an upset occurring near the end of a sample period was not much smaller.

If the sampling frequency were increased then the upset would be noticed as soon as it happened and a more 


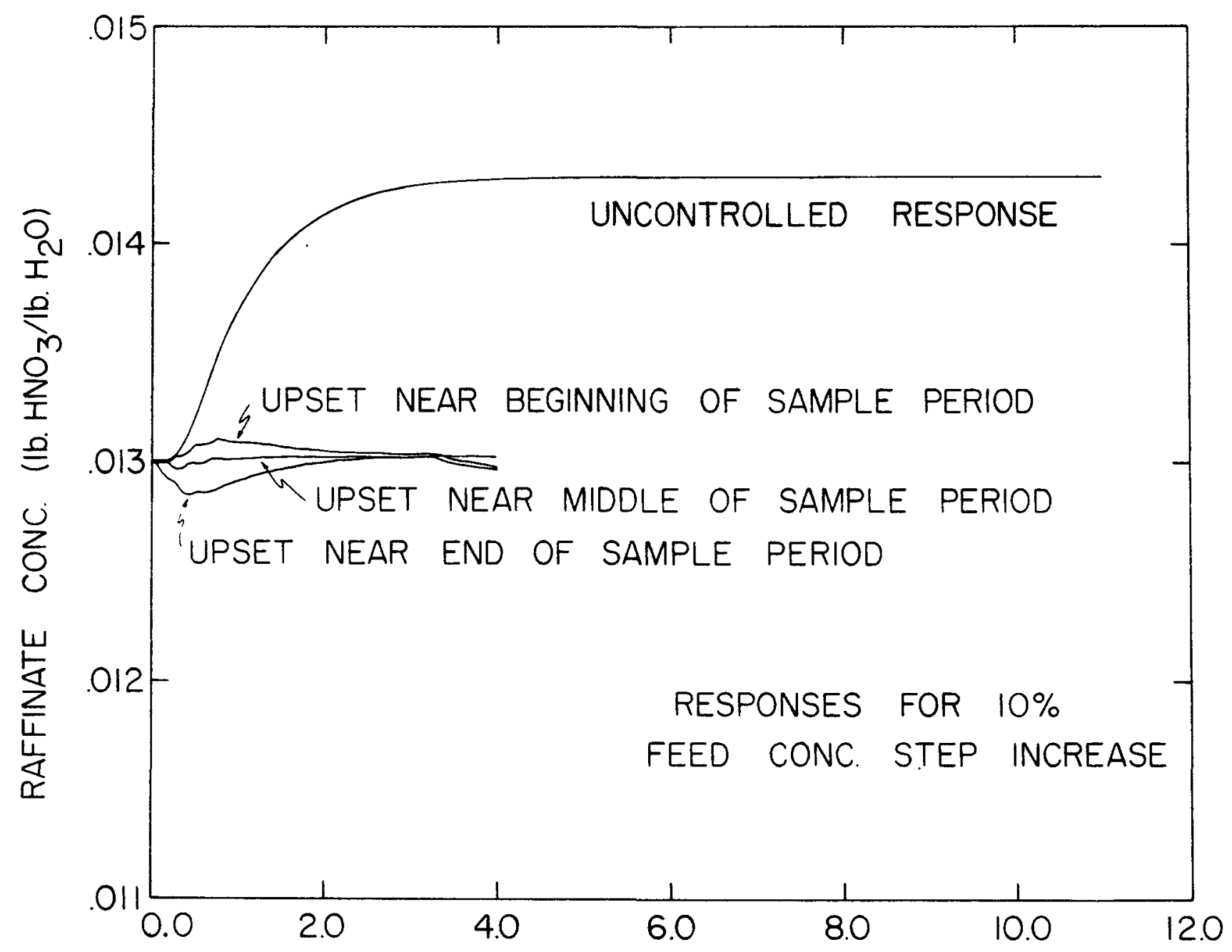

TIME (HOURS)

Figure 14. Responses showing that effect of predictive control over uncontrolled raffinate response depends upon relation of control cycle time and upset time 
exact digital compensation curve could be used. This is because the digital compensation curve would not have to compensate for errors resulting from the fact that the upset was not noticed as soon as it occurred.

Comparison of the responses in Figure 14 with those in Figure 12 shows that predictive control gives better regulation of the pulse column. Predictive control does not give rise to oscillations in the output like feedback control.

Figure 15 shows the effect of predictive control acting on a multiple feed upset. A 10 percent increase was stepped into the column and this was followed one hour later by another 10 percent increase. Figure 15 shows that the steady state predictive gain term was not accurate because there is some offset in the predictive control response. Figure 16 shows the response of predictive control plus a feedback trimmer to the same inputs as in Figure 15. The feedback trimmer corrected this offset error, hence demonstrating the need for this type of control in addition to the predictive control algorithm. The predictive control algorithm regulates the major monitored upsets and the feedback trimmer eliminates any offset errors that resulted be-cause the predictive control model was not accurate. Upsets in the chemical process industry are not always large sudden upsets. They may sometimes tend to be gradual 
45 


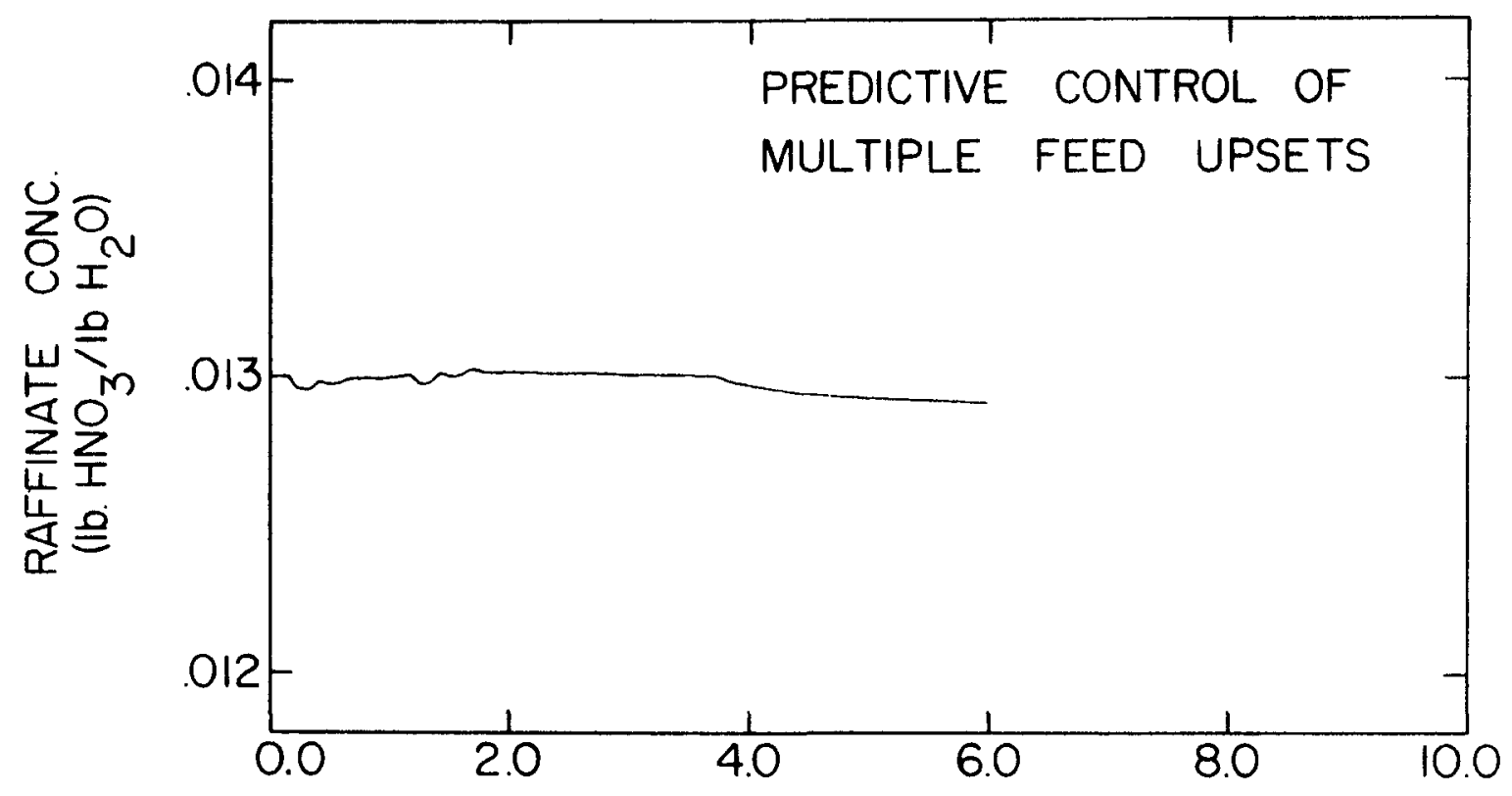

TIME (HOURS)

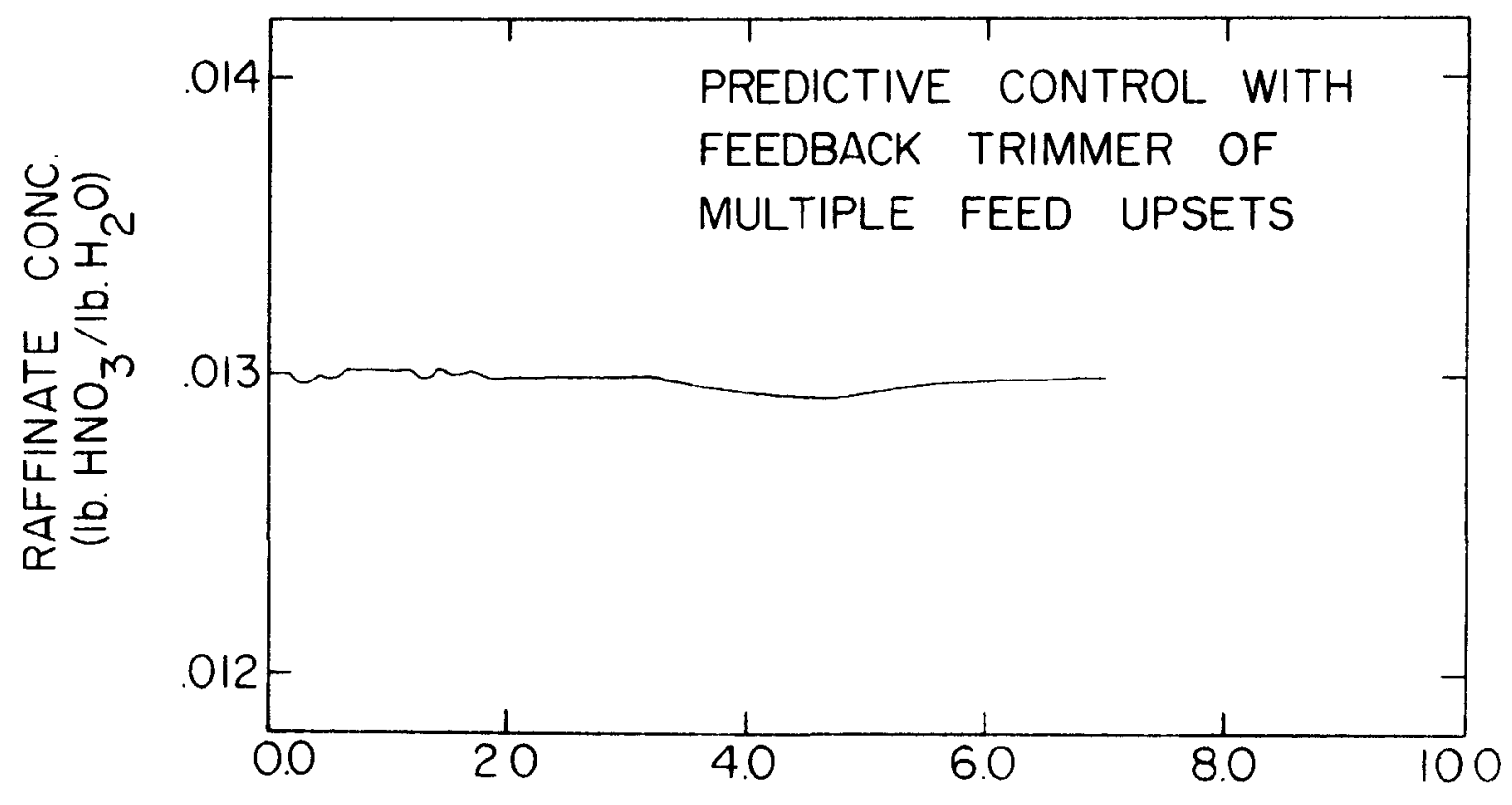

TIME (HOURS) 
changes. Such an upset may be approximated by a ramp input. Figure 17 shows the predictive control response to a 20 percent increase in feed over a period of four hours. Predictive control was able to regulate this type of an upset quite well. 


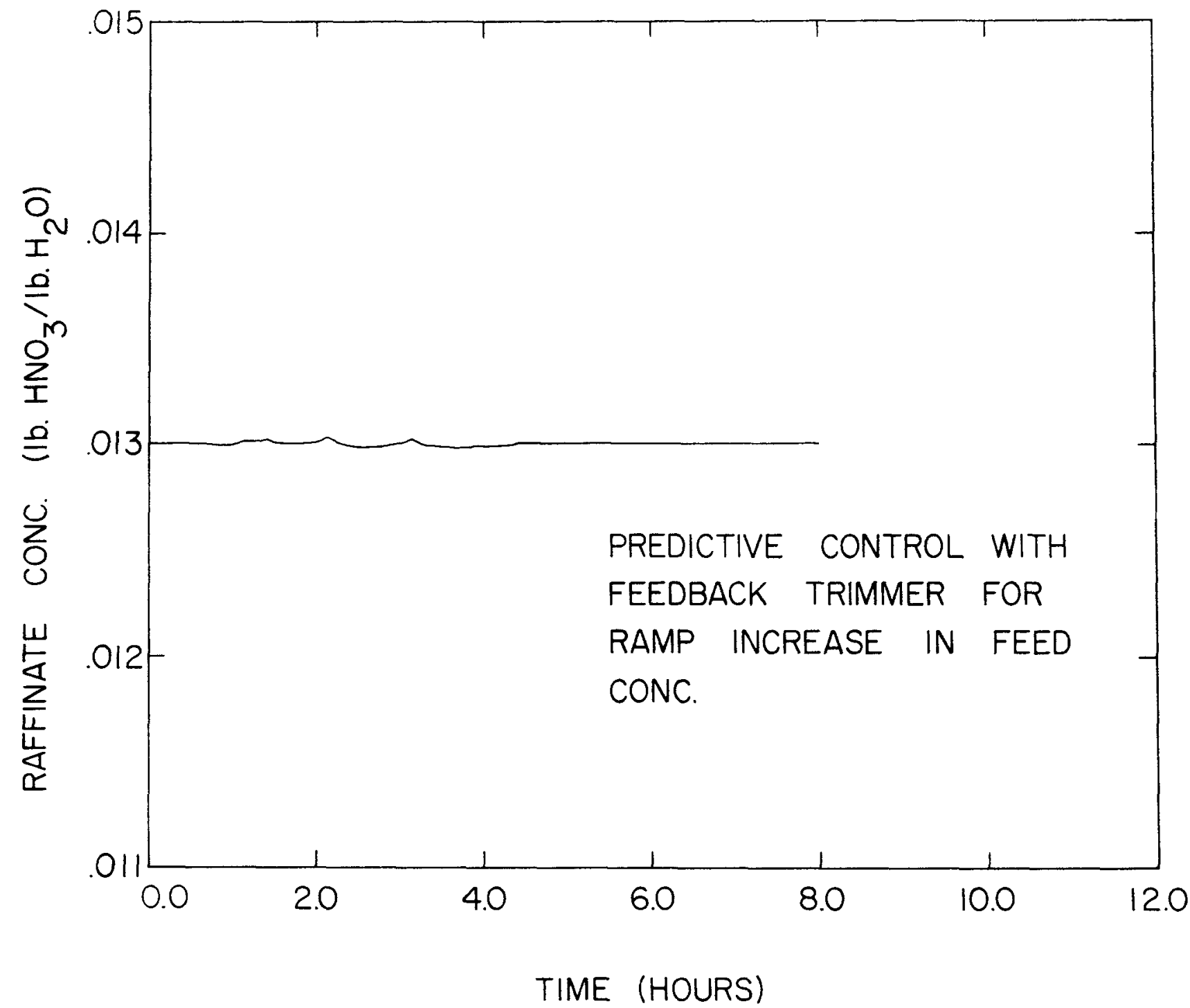
in feed concentration 
CONCLUSIONS

1. The analog model used to simulate the pulse column gave dynamic responses similar to experimental data.

2. Feedback control applied by the PDP-8/L minicomputer gave responses similar to those obtainable by a continuous conventional controller.

3. For a given sampling frequency the feedback control settings became smaller as the upsets became smaller if good regulation was desired.

4. Predictive control was more effective in regulating the output of the pulse column than was feedback control.

5. The PDP-8/L minicomputer was able to effectively monitor the system, measure input data, and implement an advanced form of control, predictive control. 


\section{LITERATURE CITED}

1. Biery. J. C. and Boylan, D. R. Dynamic simulation of a liquid-liquid extraction column. Industrial and Engineering Chemistry Fundamentals 2: 44-50. 1963.

2. Cadzow, J. A. and Martens, H. R. Discrete-time and computer control systems. Englewood Cliffs, N.J., Prentice-Hall, Inc. 1970.

3. Di Liddo, B. A. and Walsh, T. J. Computer simulation of pulse columns. Industrial and Engineering Chemistry 53: 801-804. 1961 .

4. Evans, D. R. Dynamic testing in the control of a pulse column. Unpublished Ph.D. thesis. Ames, Iowa, Library, Iowa State University. 1965.

5. Harris, J. T. and Schechter, R. S. The feedforward control of a chemical reactor. Industrial and Engineering Chemistry Process Design and Development 2: 245-252. 1963 .

6. Lee, T. H., Adams, G. E. and Gaines, W. M. Computer process control: modeling and optimization. New York, N.Y., John Wiley \& Sons, Inc. 1968.

7. Luyben, W. L. Process modeling, simulation, and control for chemical engineers. New York, N.Y., McGrawHill Book Company, Inc. 1973.

8. Luyben, W. I. and Gerster, J. A. Feedforward control of distillation columns. Industrial and Engineering Chemistry Process Design and Development 3: 374-381. 1964.

9. Mosler, H. A., Koppel, L. B. and Coughanowr, D. R. Process control by digital compensation. American Institute of Chemical Engineers Journal 13: 768-778. 1967.

10. Mosler, H. A., Koppel, L. B. and Coughanowr, D. R. Sampled-data, proportional-integral control of a class of stable processes. Industrial and Engineering Chemistry Process Design and Development 6: 221-225. 1967.

11. Murrill, P. W. Automatic control of processes. Scranton, Pa., International Textbook Company. 1967. 
12. Savas, E. S. Computer control of industrial processes. New York, N.Y., McGraw-Hill Book Company, Inc. 1965.

13. Shinskey, F. G. Process-control systems. New York, N.Y., McGraw-Hill Book Company, Inc. 1967.

14. Smoot, L. D. and Babb, A. L. Mass transfer studies in a pulsed extraction column. Industrial and Engineering Chemistry Fundamentals 1: 93-103. 1962.

15. Troutman, P. H. and Consiglio, J. A. Simulation of a solvent extraction pulsed column. U.S. Atomic Energy Commission Report TID-12472 (Technical Information Service Extension, AEC). Oct. 1958.

16. Van Dij.ck, W. J. D. Process and apparatus for intimately contacting fluids. U.S. Patent No. $2,011,186$. 1935 .

17. Watjen, J. W. and Hubbard, R. M. The dynamic behavior of a pulsed-plate extraction column. American Institute of Chemical Engineers Journal 9: 614-619. 1963. 


\section{ACKNOWLEDGMENTS}

The author wishes to express his appreciation to Dr. L. E. Burkhart for his guidance and patience during the writing of this thesis. 